\title{
La lectura de los Aerolitos de Carlos Edmundo de Ory en contextos interculturales: una experiencia en una escuela polaca
}

The reading of the Aerolitos by Carlos Edmundo de Ory in intercultural contexts: an experience in a Polish school.

Milagrosa Parrado Collantes Departamento de Didáctica de la Lengua y

la Literatura.

Universidad de Cádiz milagrosa.parrado@uca.es

Agnieszka Wilczyńska Departamento de Filología Hispánica.

Universidad de Łódź agnieszka.wilczynska@gmail.com

\section{Resumen}

Este artículo es el resultado de las investigaciones llevadas a cabo durante el curso 2015 en el colegio Publiczne Gimnazjum nr 26 im. Mikołaj Reja, situado en la ciudad de Łódź, en Polonia (con la colaboración de algunos docentes del centro), tomando como base otra propuesta de fomento lector realizada en la ciudad de Cádiz. A través de este estudio pretendemos demostrar que la literatura mediante la lectura de los clásicos literarios, en general; y, de Carlos Edmundo de Ory, en particular; rebasa fronteras uniendo, a través de los temas universales y la propia VIDA, a adolescentes de distintos ámbitos culturales y geográficos, en nuestro caso, estudiantes polacos y españoles.

\begin{abstract}
This paper has been configured as a result of the investigation accomplished during the year 2015 in the school Publiczne Gimnazjum nr 26 im. Mikołaj Reja located in Łódź (Poland). As well, this study has been carried out considering another fulfilled project about the promotion of reading in the city of Cadiz.

By this investigation we claim that Literature doesn't have borders through the study of literary classic authors in general, and Carlos Edmundo de Ory particularly. Furthermore this teaching is connected by the feelings and the LIFE of the teenagers from different cultural and geographic situations, Polish and Spanish teenagers in our case.
\end{abstract}

Palabras clave: Experiencia de aula, Clásicos literarios, Carlos Edmundo de Ory, Fomento de la lectura, Educación Secundaria, Interculturalidad

Keywords: Classroom experience, Literary classic authors, Carlos Edmundo de Ory, Promotion of reading, Secondary School, interculturality 


\section{Introducción}

La idea de incorporar y fomentar la lectura de Carlos Edmundo de Ory entre los jóvenes polacos surgió, sobre todo, después de muchas conversaciones e intercambios de experiencias entre los profesores españoles y polacos (Romero y Wilczyńska, 2016). Las tertulias de ámbito profesional y personal propiciaron a las autoras la idea de comprobar si la expresión artística oryana podía tener la dimensión universal y encontrar su espacio por encima de las fronteras. Y es esta palabra, "frontera", la que desempeñará aquí un papel primordial y, sobre todo, comprobaremos si la poesía de Carlos Edmundo de Ory puede tener un valor universal en un contexto diferente a España, en nuestro caso, Polonia, posibilitando una lectura intercultural de este autor. En segundo lugar, la incorporaremos en un ambiente juvenil de estudiantes polacohablantes maternos cuya L2 es el español para comprobar su recepción y averiguar si estos alumnos superan las barreras y los límites para desarrollar su propio pensamiento, la reflexión, la creatividad y el deseo de expresarse.

\section{El contexto: espacio y tiempo de nuestra actuación}

El curso escolar 2015/2016 fue nombrado El año de la Escuela Abierta. Como argumenta la exministra de Educación, Joanna Kluzik-Rostkowska, quien, con acuerdo a la ley escolar, estableció las directrices básicas de la política escolar para este año "La escuela abierta es una escuela que no se cierra a la cultura, arte, deporte y el ambiente local. Sabe aprovechar de lo que la rodea". Una de las direcciones anteriormente mencionadas fue el desarrollo de las competencias de lectura y el fomento de esta entre los niños y adolescentes. De acuerdo con la ley vigente en Polonia, cada escuela debía incluir estas directrices mediante el desarrollo de propuestas que se acomodaran tanto al programa del trabajo ofrecido por el Ministerio como al curriculum escolar preparado anualmente.

Como respuesta a la iniciativa presentada por el Gobierno, el Instituto Público número 26 de Mikołaj Rej en Łódź (PG26) decidió nombrar el mes de octubre como el mes de la literatura española. En la acción tomaron parte las profesoras iniciadoras del proyecto, Milagrosa Parrado Collantes (Universidad de Cádiz) y Agnieszka Wilczyńska (PG26 y Universidad de Łódź); el profesor bibliotecario del centro (Marcin Matusiak); y la profesora de lengua y literatura polaca (Małgorzata Wójcik). Durante todo el mes en la biblioteca escolar los alumnos pudieron leer distintas biografías de autores españoles de renombre, como por ejemplo, Federico García Lorca, Antonio Machado, Juan Ramón Jiménez, Eduardo Mendoza, Carlos Ruíz Zafón... Sin sombra de duda, la presentación del material biográfico no es una manera eficaz para llamar la atención de los alumnos adolescentes, así que, como una de las estrategias de desarrollo personal, creativo y literario del alumnado y, a la vez, la realización de las instrucciones mandadas por el Ministerio de Educación, se decidió preparar una unidad didáctica dedicada a un autor no tan famoso como los mencionados anteriormente y que, por supuesto, rebasa el canon literario y escolar establecido tanto en España como en la enseñanza de lengua y literatura española, en este caso, en Polonia; hablamos de Carlos Edmundo de Ory.

Por nuestra parte, desde la Universidad de Cádiz, en colaboración con la Fundación Carlos Edmundo de Ory, ya habíamos puesto en práctica la poética e ideario del autor 
gaditano en el I.E.S. Drago. Nuestra propuesta didáctica se centró en el análisis de cuatro textos oryanos que coincidían con cuatro grandes temas universales de la literatura: el amor, la muerte, la angustia y la propia literatura, tomando como estrategia metodológica un taller de creación de Aerolitos a partir de los propios oryanos para el desarrollo de la competencia literaria.

Como objetivos principales nos propusimos: a) dar a conocer la figura de Carlos Edmundo de Ory, $b$ ) acercar su obra y disfrutar de la lectura de la misma, $c$ ) identificar los temas universales en los textos del poeta gaditano y $d$ ) disfrutar con la lectura de autores clásicos. Como podemos comprobar, estos temas son relativos, sobre todo, a los sentimientos, ¿y quién mejor que los propios adolescentes para hablar de sentimientos? ¿Qué chico no ha sufrido la angustia de no saber quién es? Nos referimos a esa tristeza medular (De Ory, 2006, p. 37 [Poema: "En un café"]) de la que habla Carlos Edmundo y que impregna muchos de sus poemas. Además, ¿qué adolescente no ha sufrido el más maravilloso y terrible de los amores? Igualmente, todos en esta vida hemos perdido a un ser querido y con Carlos Edmundo aprendemos que la muerte no tiene por qué ser siempre un tránsito físico. Todas estas cuestiones están envueltas de ese hilo poético, de esa magia que nos invade al leer los textos del escritor gaditano, porque los adolescentes, lo creamos o no, también hablan de literatura y tan solo hay que saber tocar las teclas adecuadas, teclas que encontramos en los textos oryanos y que desprenden una música psicodélica, frenética, senxual según la terminología de (Parrado, 2013), brillante y tierna (Parrado, 2015).

Tras las experiencias en el Centro I.E.S. Drago en Cádiz y en el colegio Publiczne Gimnazjum nr 26 Mikołaj Reja en Łódź (en adelante, PG26), podemos establecer como objetivos principales y conjuntos desde una visión intercultural de la obra de Carlos Edmundo de Ory: a) internacionalizar la figura de Carlos Edmundo de Ory; b) disfrutar de la lectura de autores en la L2 que están aprendiendo los alumnos (español en este caso); c) disfrutar con la lectura de Carlos Edmundo de Ory; d) incentivar el pensamiento crítico en el alumnado; e) fomentar la escritura creativa y/o argumentativa en los adolescentes; $y, f$ ) identificar los temas universales en la obra oryana y en la vida de los adolescentes en general, tanto españoles como polacos.

\section{Carlos Edmundo de Ory}

\section{a) Carlos Edmundo de Ory, ese famoso desconocido}

Antes de entrar en materia, tendríamos que hacer una breve referencia bibliográfica del autor que estamos tratando, ya que hemos de tener en cuenta que la figura que estamos tratando es, por así decirlo, un tanto atípica, tanto en el panorama de la poesía española, como en el panorama escolar.

Por otra parte, el contexto de educación literaria en el que desenvuelven los alumnos polacos de nuestra experiencia evidentemente se rige a la literatura polaca y si se hace referencia a autores canónicos de la literatura hispánica, los autores a los que se hace alusión se podría resumir en un nombre, máximo exponente del canon español: Miguel de Cervantes. El acercamiento a otros autores hispánicos se hace mediante talleres y sesiones que los profesores elaboran en el centro educativo, como por ejemplo, una exposición de autores españoles que se realizó en la biblioteca escolar en el mes de octubre que incluía a escritores como Antonio Machado, Juan Ramón Jiménez, Federico 
García Lorca, Eduardo Mendoza o Carlos Ruiz Zafón. Como vemos, estos autores se encuentran en una posición bastante privilegiada en el canon escolar español, siendo los escritores más estudiados también para pasar la prueba de Selectividad. Con respecto al canon escolar español, la lista obviamente se amplia, aunque Carlos Edmundo de Ory también queda relegado a un segundo o directamente a ningún plano En la tesis en curso de realización de Parrado se atestigua el olvido editorial de Carlos Edmundo de Ory a partir del análisis de cinco libros de texto de editoriales importantes españolas.

Carlos Edmundo de Ory (Cádiz, 27 de abril de 1923 - Thézy — Glimont, Francia, 11 de noviembre de 2010). Poeta, narrador, ensayista, articulista y traductor. Hijo del poeta modernista Eduardo de Ory en cuya biblioteca el autor toma contacto, reafirmándose en su vocación poética, con autores como Rubén Darío, Gustavo Adolfo Bécquer, Francisco Villaespesa, Paul Verlaine, Juan Ramón Jiménez o Leopoldo Lugones. En 1945 (junto a Eduardo Chicharro y Silvano Sernesi) funda el Postismo, broche de oro de las Vanguardias, además de brecha en la sociedad inmovilista franquista del momento y de la poesía social. Dos revistas se publican ese año, Postismo y La Cerbatana las cuales cuentan tan solo con un número por su natural irreverencia. Como consecuencia, el Régimen franquista los tachará directamente de locos y los adscritos a la poesía social de frívolos.

Tras varias desazones literarias y personales, el autor viaja a Francia con una beca y poco a poco irá fijando allí su residencia. Así, tras una vida de nómada poeta muere la madrugada del once de noviembre de 2010. Sus cenizas reposan junto al mar en la Glorieta Carlos Edmundo de Ory, en el corazón de la Alameda Apodaca, donde se erigió una estatua en su honor el pasado día 27 de abril de 2015, coincidiendo con el cumpleaños del autor.

\section{b) Los Aerolitos y su inclusión en el canon formativo para una propuesta didáctica}

Para poder llevar a cabo nuestra propuesta, en primer lugar tenemos que explicar qué es un Aerolito; en el plano literal, si atendemos al DRAE (2014):

\section{.aerolito}

De aero- y lito.

1.m. Meteorito, o fragmento de él, que cae sobre la Tierra.

Tras esta definición en un primer momento entrevemos el carácter supersónico de estos textos. Si atendemos al plano metafórico, vemos que algunos críticos, como José Ramón Ripoll han teorizado acerca del término oryano.

En el número tres de la revista digital Poemad, Ripoll (2013) nos ofrece la siguiente defnición de los Aerolitos:

Como suele ocurrir con toda la obra de Ory, los aerolitos obedecen a un proceso acumulativo, a un work in progress. [...] De las voces griegas aer-aeros-aire, pero también oscuridad-y litos - piedra arrojadiza, y al tiempo, piedra preciosa-, cada aerolito es un destello que surge del vacío, de la negra noche, y nos invita a regresar al origen tras haber recibido la descarga de su luminosidad. Lo importante de cada aerolito ya no es su forma ni textura, sino el hueco que deja en nuestro territorio: hueco profundo, grieta deshabitada, caverna en cuyas sombras sucede no ya lo que creíamos realidad, como en el platónico acertijo, sino la vibración rotunda de lo real. En esa 


\begin{abstract}
introspección, mirada o viaje hacia el centro de la Tierra y hacia el centro del ser, el poeta conecta su memoria oriental con el hilo subterráneo que sostiene la tradición de nuestras negaciones [...] Los aerolitos de Ory se diferencian de otras literaturas breves en que precisamente no son literatura, sino ramificaciones nerviosas de un núcleo vitalísimo que nos recuerda en todo momento que estamos vivos [el subrayado es nuestro].
\end{abstract}

Hemos querido rescatar estas palabras de José Ramón Ripoll porque, bajo nuestro punto de vista, los Aerolitos son un ente vivo literario, son ese work in process al que remite Ripoll que además se configuran como aforismos que engloban la esencia literaria y personal de Carlos Edmundo, su lenguaje y su creación, además de ajustarse a una temática que hemos establecido como punto de partida: las sensaciones y emociones de los alumnos con los que vamos a trabajar. Bajo nuestro punto de vista, los Aerolitos suponen una herramienta perfecta para establecer la comunicación directa entre los receptores (nuestros alumnos) y el propio texto, en nuestro caso los Aerolitos, o en palabras de Sánchez Corral (2015, p. 297):

\begin{abstract}
El enfoque centrado en la recepción asume los planteamientos de un modelo interactivo, de modo que la lectura literaria se entiende ahora como el resultado de la interacción entre las aportaciones del lector y las del texto. El modelo interactivo describe la lectura como un conjunto de actividades en el que los procesos ascendentes y descendentes combinan e interrelacionan sus procedimientos de modo simultáneo; de ese modo en el proceso receptor se integran las actividades cognitivas que se suceden en la actividad lectora, desde las anticipaciones a la concreción de la interpretación.
\end{abstract}

Para una concreción de los Aerolitos hemos tomado como base a De Vicente-Yagüe, para configurar una rúbrica con nuestra propuesta didáctica en la que incluimos a Carlos Edmundo de Ory y sus Aerolitos en el canon formativo. En su artículo, De VicenteYaguie (2015, pp. 301-303) hace una distinción entre los diferentes tipos de canon: canon literario-filológico; canon escolar; canon de literatura infantil y juvenil; canon de aula; canon formativo. Nosotros haremos hincapié en el canon formativo ya que, bajo nuestro punto de vista, es el más completo y, además, el que más se ajusta a nuestra investigación: "el canon formativo supone una composición del canon escolar, el canon de aula y el canon de literatura infantil y juvenil. Esta selección se mueve por unos criterios didácticos y formativos y pone el acento en los procesos de recepción de los textos literarios [el subrayado es nuestro]" (Vicente-Yagüe, 2015, pp. 300-303).

Además, podemos extraer algunos objetivos y conclusiones de esta relación entre valores educativos transmitidos en las obras y adecuación de obras a los gustos e intereses de los alumnos, ya que nuestra propuesta con los alumnos polacos se llevó a cabo en las clases de tutoría. Por otro lado, en este proceso de recepción haremos hincapié en la figura del docente como mediador: creemos firmemente en que la recepción de un autor como Carlos Edmundo de Ory necesita esta figura para que su recepción sea lo más completa y posible en este proceso de emociones y sentimientos que hemos llevado a cabo.

\begin{tabular}{|l|l|}
\hline $\begin{array}{l}\text { Valores educativos transmitidos en las } \\
\text { obras: }\end{array}$ & \\
\hline $\begin{array}{l}\text { Selección de obras que supongan una } \\
\text { transferencia de valores y permitan educar } \\
\text { a un alumnado crítico capaz de solventar }\end{array}$ & $\begin{array}{l}\text { En el plano personal, Carlos Edmundo de } \\
\text { y personales muy marcados; de hecho, su }\end{array}$ \\
\hline
\end{tabular}




\begin{tabular}{|c|c|}
\hline $\begin{array}{l}\text { conflictos y de actuar adecuadamente en } \\
\text { su día a día. }\end{array}$ & $\begin{array}{l}\text { incorruptibilidad tanto en el arte como en } \\
\text { la vida es uno de sus rasgos } \\
\text { característicos. Por otra parte, otro de esos } \\
\text { rasgos es el compromiso que mantiene } \\
\text { para con la libertad el poeta gaditano y } \\
\text { quizás es por eso por lo que el autor } \\
\text { decide mantenerse al margen en todo } \\
\text { momento; pero no nos confundamos, que } \\
\text { se sitúe al margen, no quiere decir que no } \\
\text { se implique y ese compromiso se realiza } \\
\text { siempre a través de la literatura. } \\
\text { Desde un punto de vista literario, además } \\
\text { de Aerolitos de carácter inter / } \\
\text { hipertextual, nos encontramos con otros } \\
\text { de un carácter más filosófico y reflexivo } \\
\text { [Ver listado } 1 \text { al final del artículo]. Estos } \\
\text { Aerolitos pueden ser muy útiles si } \\
\text { queremos, por ejemplo, fomentar el } \\
\text { debate en clase o la escritura } \\
\text { argumentativa, lo que desemboca en el } \\
\text { desarrollo de un espíritu crítico en el } \\
\text { alumno. }\end{array}$ \\
\hline \multicolumn{2}{|l|}{$\begin{array}{l}\text { Adecuación de obras a los gustos e } \\
\text { intereses de los alumnos: }\end{array}$} \\
\hline $\begin{array}{l}\text { Obras atractivas por su temática o } \\
\text { recursos expresivos }\end{array}$ & $\begin{array}{l}\text { Los Aerolitos de Carlos Edmundo de Ory } \\
\text { tratan también los temas universales muy } \\
\text { presentes en la vida de los alumnos, como } \\
\text { por ejemplo, el amor, la brevedad de la } \\
\text { vida, la muerte, la angustia existencial, la } \\
\text { propia literatura... [Véase listado } 2 \text { al final } \\
\text { del artículo]. }\end{array}$ \\
\hline $\begin{array}{l}\text { Selección de obras adecuadas a la edad de } \\
\text { los alumnos, para ayudar en su proceso } \\
\text { lector }\end{array}$ & $\begin{array}{l}\text { Los Aerolitos sirven para hacer referencia } \\
\text { a otras obras literarias que podemos } \\
\text { acercar a nuestro alumnado. }\end{array}$ \\
\hline
\end{tabular}

Cuadro 1. Valores educativos

Experiencia en el centro Publiczne Gimnazjum nr 26 im. Mikołaj Reja, Lódź, Polonia

\section{a. Material didáctico}

La preparación de una unidad didáctica dedicada al autor de oriundez completamente diferente a la de los alumnos polacos fue un reto tanto para los profesores de la Universidad de Cádiz como para los de la Universidad de Lodz. Primero, fue necesario 
modelar y estructurar un plan didáctico para que, finalmente, se decidiera introducir el uso de los Aerolitos en dos asignaturas diferentes: en las clases de la literatura y lengua polacas (2 y 3 de E.S.O.) y en las clases de la tutoría (1 de E.S.O.). En este último caso la profesora dedicó una unidad lectiva de 45 minutos (1 de E.S.O.) para escuchar las opiniones acerca de los Aerolitos presentados en la presentación de Power Point. La actividad sirvió para conocer mejor a los alumnos nuevos, observar su trabajo en grupos, manera de analizar, sacar conclusiones y el grado de timidez en cuanto a la expresión oral en público. Las conclusiones de los alumnos constituirán una base para las charlas futuras durante las clases de tutoría.

Las clases de $2^{\circ}$ y $3^{\circ}$ de E.S.O. tuvieron forma de conversación relacionada con la expresión escrita (la clase dirigida por la profesora del polaco). La clase de $1^{\circ}$ E.S.O tuvo la forma de una charla didáctica entre la profesora y los alumnos que presentaremos más adelante (la clase dirigida por la profesora de ELE y a la vez tutora de $1^{\circ}$ E.S.O.).

Las autoras del proyecto prepararon una presentación Power Point con la biografía del autor que entregaron a los profesores correspondientes para su contextualización y puesta de largo entre los docentes. Además, hemos de resaltar una etapa clave: la selección de los Aerolitos adecuados y posibles de traducir al polaco; en este sentido se intentó cumplir con los objetivos siguientes:

- Realizar una traducción lo más fiel posible

- Evitar la ambigüedad

- Seleccionar Aerolitos adecuados con respecto a la edad del alumnado

- Evitar juegos de palabras imposibles de traducir de una manera fiel

- Prevenir una falta de referencias a la cultura meramente española

Después de elaborar una lista de objetivos, se seleccionaron diez Aerolitos traducidos al polaco y se diseñó una presentación Power Point para las profesoras como único material de soporte didáctico. El material fue limitado para no despistar a los alumnos y no darles ningún tipo de andamiaje, ya que la idea del proyecto fue incentivarlos a descubrir y presentar sus propias reflexiones y pensamientos, además de retomar la tradición oral y de conversar siguiendo la coordenada alumno-maestro y su intercambio de opiniones acerca de aspectos esenciales y sentimientos universales.

\section{b. Las clases de la literatura polaca}

La profesora de la literatura y lengua polaca decidió presentar la idea en dos niveles educativos: $2^{\circ}$ y $3^{\circ}$ de E.S.O. El promedio de notas en estos dos grupos es uno de los más bajos porque entre los grupos mencionados hay muchos estudiantes con dificultades de estudio, además de estudiantes en contexto de riesgo.

En la clase tomaron parte 46 alumnos, como hemos dicho, de $2^{\circ}$ y $3^{\circ}$ de E.S.O. La profesora utilizó un conjunto de Aerolitos traducidos al polaco por las autoras del presente trabajo como pretexto para hablar y mantener una conversación con los alumnos. Después de la presentación biográfica del autor y el intercambio de opiniones, la profesora le pidió a los alumnos que escogieran un Aerolito y escribieron su propia interpretación del mismo. La docente les explicó que todos los alumnos que tomaban 
parte en la clase estaban obligados a devolver sus reflexiones. Las redacciones fueron comprobadas por la profesora para que los alumnos pudieran recibir la retroalimentación acerca de los errores gramaticales y estilísticos que habían cometido. La profesora decidió no incluir la corrección gramatical a la evaluación y evaluó solamente el proceso de creación, la manera de expresar la opinión sobre la idea y la creatividad.

La docente recibió una ficha con rúbricas para evaluar la actividad y orientarse mejor a la hora de preparar sus propias reflexiones. Estas rúbricas están divididas en tres partes: motivación, conversación y escritura y se presentan de esta manera:

\begin{tabular}{|l|l|l|l|l|}
\hline Categoría & Pregunta & Sí & No & Parcialmente \\
\hline \multirow{4}{*}{ MOTIVACIÓN } & $\begin{array}{l}\text { ¿Les motivó la idea de participar en } \\
\text { un proyecto internacional a tomar } \\
\text { parte activa en la actividad? }\end{array}$ & $\mathrm{X}$ & & \\
\cline { 2 - 5 } & $\begin{array}{l}\text { ¿Les gustó a los alumnos la idea de } \\
\text { conocer a un autor completamente } \\
\text { desconocido y exótico? }\end{array}$ & $\mathrm{X}$ & & \\
\hline \multirow{2}{*}{ CONVERSACIÓN } & $\begin{array}{l}\text { ¿Les motivó la actividad a tomar } \\
\text { parte en la conversación? }\end{array}$ & $\mathrm{X}$ & & \\
\cline { 2 - 5 } & ¿Fue una conversación creativa? & $\mathrm{X}$ & & \\
\hline \multirow{2}{*}{ ESCRITURA } & ¿Les motivo a la escritura? & & & $\mathrm{X}$ \\
\cline { 2 - 6 } & ¿Fue una escritura creativa? & & $\mathrm{X}$ \\
\hline
\end{tabular}

Cuadro 2: Rúbricas para el profesorado.

1.Observaciones de la profesora:

Aunque el grupo de la clase experimental es uno con el mayor número de alumnos menos dotados, con dislexias y trastornos de actitud, los alumnos parecían muy interesados en la biografía y la creación del autor español, ya que fue su primer encuentro con un escritor proveniente de España.

Los alumnos tomaron parte en el intercambio de opiniones empezando desde las más obvias pero, por otra parte, llegando a unas reflexiones más profundas que revelaron incluso algunos problemas personales. Por ello, para algunos la actividad tuvo una dimensión personal que les ayudó a expresar sus dudas y problemas. Los estudiantes querían hablar con la profesora, pero a la hora de escribir no presentaron todas sus capacidades. Todos los trabajos devueltos por escrito fueron revisados por la profesora de polaco, analizados con los alumnos $\mathrm{y}$, finalmente, entregados a la profesora de español para un análisis más profundo.

Cinco personas de dos grupos no devolvieron sus trabajos, por eso recibieron la nota más baja - 1 . El resto de los alumnos recibió notas de 2 a 5 . 
c. Descripción de grupos

$1.2^{\circ}$ E.S.O. "A" y $3^{\circ}$ E.S.O. "B"

PG26 dispone de cinco grupos que están en el mismo nivel educativo ( $2^{\circ}$ E.S.O.) y de 4 grupos de $3^{\circ}$ E.S.O. Los grupos tienen sus propios símbolos - en este caso el centro utiliza letras (a-e). En la presente investigación tomaron parte el grupo $2^{\circ} \mathrm{A}$ y $3^{\circ} \mathrm{B}$. En las Figuras 1 y 2 se presentan los resultados generales con el promedio de notas y la situación del grupo comparando con otros grupos del centro que están en el mismo nivel educativo.

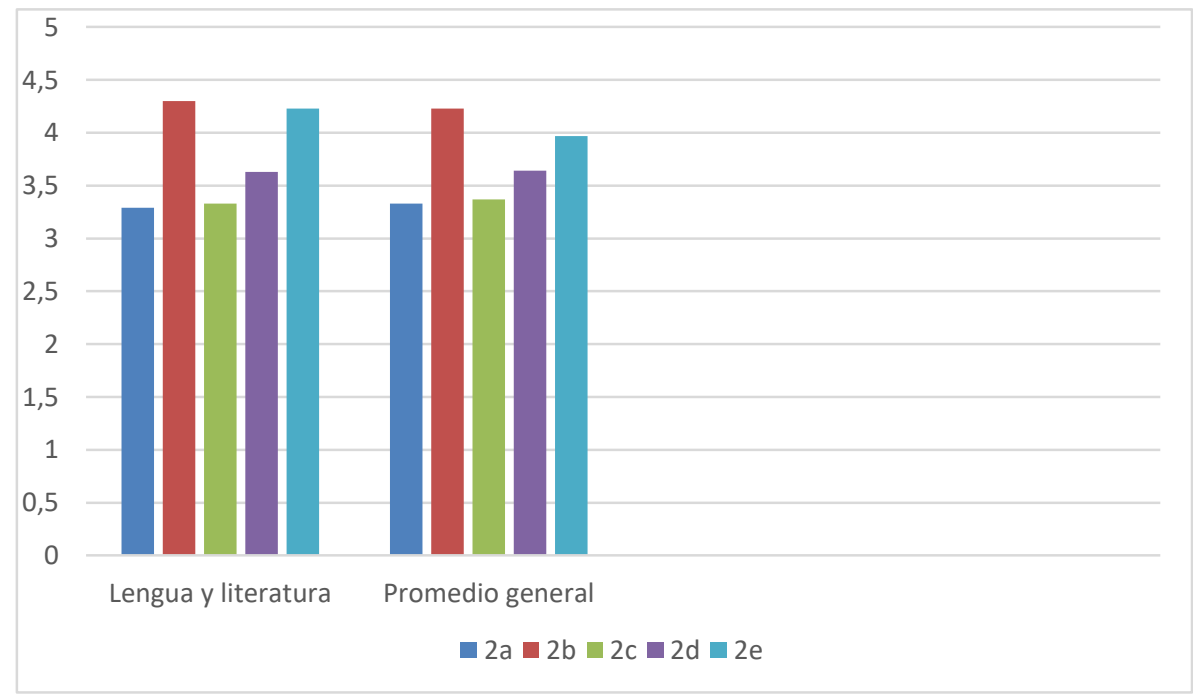

Figura 1. Resultados de $2^{\circ} \mathrm{A}$ de E.S.O.

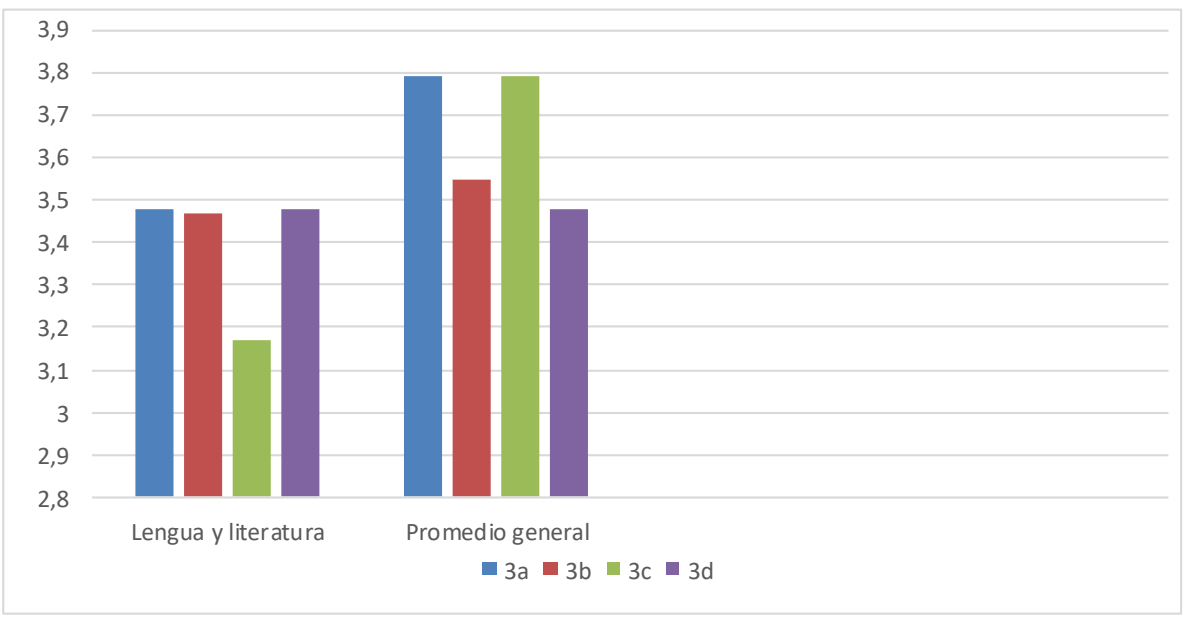

Figura 2. Resultados de $3^{\circ} \mathrm{B}$ de E.S.O.

Como es perceptible, el grupo $2^{\circ}$ A consigue las notas más bajas en general, también de la lengua polaca. Sin embargo, hay que notar que las notas de las redacciones tienen un nivel bastante elevado. El caso del grupo $3^{\circ} \mathrm{B}$ es muy similar. 
Como es podemos comprobar, el grupo $2^{\circ} \mathrm{A}$ obtiene notas más bajas en general, también de la lengua polaca. Sin embargo, hay que advertir de que las notas de las redacciones tienen un nivel bastante elevado. El caso del grupo $3^{\circ} \mathrm{B}$ es muy similar.

En los Cuadros 3 y 4 es posible observar la evaluación de las redacciones. La escuela utiliza una escala de evaluación de 1 a 6 , aunque el profesor puede designar también los signos $+\mathrm{y}-\mathrm{a}$ cada nota. Los alumnos recibieron notas correspondientes:

2 E.S.O.

\begin{tabular}{|l|l|l|l|l|l|l|l|}
\hline Nota & 1 & 2 & 3 & $3+$ & $4-$ & 4 & 5 \\
\hline $\begin{array}{l}\text { Número de } \\
\text { personas }\end{array}$ & 2 & 0 & 1 & 4 & 2 & 8 & 7 \\
\hline
\end{tabular}

Cuadro 3: Notas de $2^{\circ}$ A de E.S.O.

3 E.S.O.

\begin{tabular}{|l|l|l|l|l|l|l|l|l|l|}
\hline Nota & 1 & 2 & 3 & $3+$ & $4-$ & 4 & $4+$ & $5-$ & 5 \\
\hline $\begin{array}{l}\text { Número de } \\
\text { personas }\end{array}$ & 3 & 1 & 0 & 0 & 3 & 5 & 4 & 2 & 4 \\
\hline
\end{tabular}

Cuadro 4: Notas de $3^{\circ} \mathrm{B}$ de E.S.O

\section{d. Análisis de resultados}

Para poder realizar el análisis recibimos 46 redacciones y decidimos tener en cuenta los tres Aerolitos más elegidos por los alumnos. Los estudiantes podían elegir el Aerolito que les gustó más y escribir sus reflexiones mediante una redacción libre. Los alumnos que no consiguieron acabar el trabajo durante la clase podían terminar la tarea en casa y devolverla en el próximo encuentro con la profesora.

El Cuadro 5 que presentamos abajo representa los tres Aerolitos más populares entre los alumnos. La tercera y la cuarta columna contienen el número de estudiantes que decidieron escribir sus reflexiones acerca de este tema.

\begin{tabular}{|l|c|c|}
\hline Aerolito & 2 E.S.O. & 3 E.S.O. \\
\hline 1. Sé poeta un instante y hombre todos los días. & 6 & 6 \\
\hline 2. No soy un soñador. Soy un buscador de sueños. & 8 & 4 \\
\hline 3. Estoy cansado de mañana. & 8 & 7 \\
\hline
\end{tabular}

Cuadro 5. Tipos de Aerolitos (De Ory, 2005) 
1. Sé poeta un instante y hombre todos los días. - Poetą bądź przez chwilę, a człowiekiem codziennie.

Estudiando las reflexiones acerca del aerolito anteriormente destacado, salta a la vista una brecha muy profunda entre la vida de un poeta y la de un hombre normal y corriente (Imagen 1). Los adolescentes señalan rotundamente la personalidad de un poeta, destacando la divergencia entre el modo de pensar de los poetas y los no poetas. Además, el estudio de los trabajos por escrito revela el peculiar tipo de visión del mundo que tienen los adolescentes e, incluso, un tipo de moraleja o sermón que les gustaría transmitir. Por eso decidimos dividir el análisis en estos tres campos: la visión del poeta y poesía, la visión del hombre y el mensaje para el mundo.

Empezando con la visión del poeta, los alumnos afirman que es una persona que vive en un mundo imaginario y onírico. Lo presentan como un ente demasiado sensible y lleno de emociones, pero a la vez, empático. Una de las alumnas metaforiza la figura del poeta, diciendo que "dibuja con palabras" y también a la poesía como "cumplimiento de sueños pasajeros". La mayoría de los aprendices observa que la poesía es un momento efímero y temporal. Así, dos alumnos recurren a citar un poema de la escritora polaca Wisława Szymborska (de la que, curiosamente, Carlos Edmundo es lector y de la que hace referencia en algunas páginas de sus escritos) ganadora del premio Nobel de literatura: "Nada ocurre dos veces, ni ocurrirá. (...) Ningún día se repite, no hay dos noches iguales" (p. 29) subrayando que la vida pasa volando y es tan temporal como la poesía. Entre las redacciones aparecen también opiniones que presentan la imagen del poeta como un hombre sobrevalorado y creído al que le parece hacer una cosa muy importante y "la verdad es que son solamente poemas que la gente puede olvidar rápidamente". La palabra poeta aparece entre comillas como si el alumno quiera subrayar lo poco que valora la profesión del poeta. El alumno añade que no nacimos ni poetas ni animales. Nacimos humanos y nuestra obligación esencial es ser hombres y comportarnos de acuerdo con las normas.

Una gran parte de los estudiantes admite que el hombre normal y corriente no puede ser artista porque tiene que ser muy responsable cada día. Tiene que enfrentarse con los problemas de lo cotidiano, le atacan las emociones negativas de los problemas que tiene y está obligado a hacerles frente; lo que no puede hacer es huir al mundo imaginario ya que tiene que tener los pies en el suelo y sufrir mucho en la vida. Por otro lado, algunos alumnos defienden a la persona del poeta escribiendo que es una parte de su personalidad. Una estudiante escribe: Si sabes vivir un momento de gran emoción y describirlo "dibujando con palabras" no puedes arrancar esta parte de tu ser. Por eso habría que plantearse una pregunta si es posible ser poeta un instante si serlo constituye una parte de ti mismo. Otra alumna argumenta que en el caso de perder la propia personalidad el hombre no puede llamarse hombre sino su copia.

Para finalizar, pasaremos a las conclusiones que extraen los adolescentes. En muchos casos, la imagen de la vida que tienen es muy racional y sensata. Los alumnos mencionan que no hay que concentrarse solamente en el momento en el que estamos, sino que hay que pensar en lo pasado y en lo futuro porque esto construye nuestra vida y nuestra personalidad. Los alumnos están de acuerdo con que no hay que vivir toda la vida con pájaros en la cabeza y añaden que hay que encontrar un término medio en la vida. Se puede notar que los alumnos recurren a la filosofía horaciana de la aurea 
mediocritas diciendo que el hombre tiene que saber encontrar el tiempo para lo necesario y para la fiesta. Muchas veces subrayan que es obligatorio dedicar tiempo a la vida con otra gente, porque nuestros seres queridos necesitan nuestra atención y cariño. Una alumna observa que si entras en el mundo poético puedes hacerlo solamente por un momento para no perderse y, en consecuencia perder la vida. Añade también que puede ser peligroso quedarse estancado en lo onírico e imaginario y la vuelta a lo real puede ser difícil o incluso imposible.

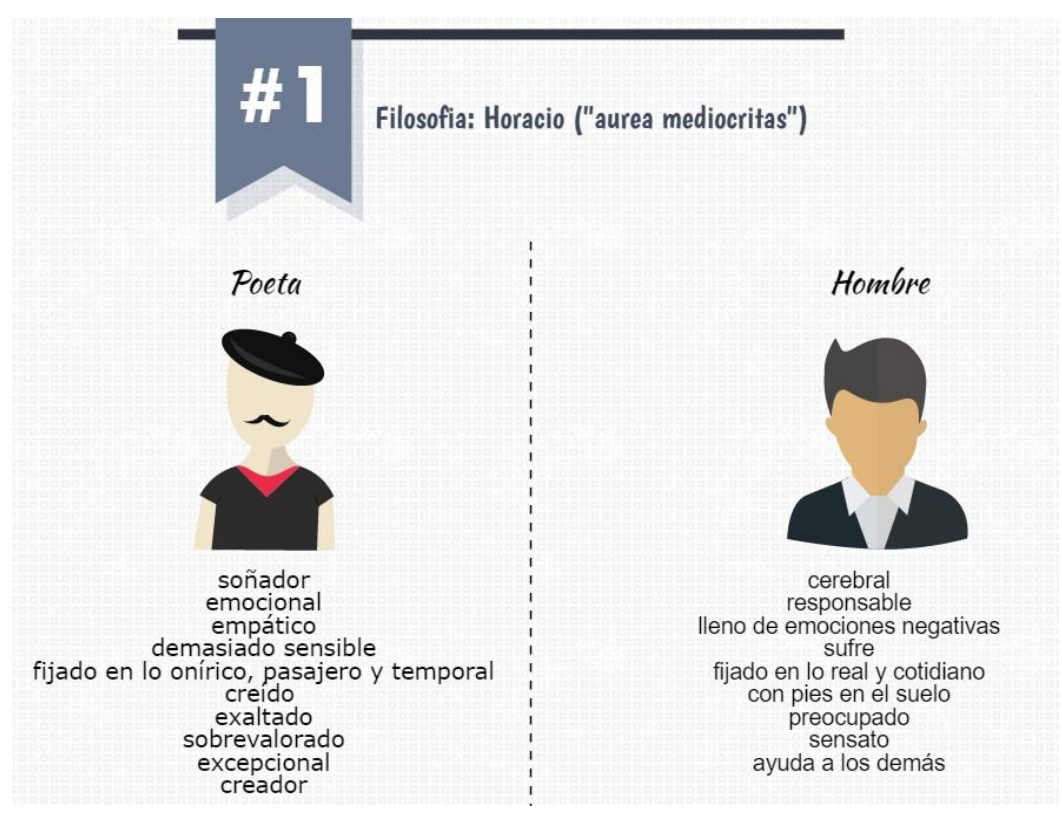

Imagen 1. Poeta/poesía vs. la gente (representación visual).

2.No soy un soñador. Soy un buscador de sueños. - Nie jestem marzycielem, jestem poszukiwaczem marzeń.

Analizando este tema es posible hacer una división muy similar a la del tema anterior (Imagen 1). En este caso (Imagen 2), los alumnos desgranan dos tipos de personajes, obviamente: el soñador y el buscador de sueños. En cuanto al soñador los alumnos creen que es una persona que tiende a pensar en cosas poco probables o imposibles de cumplir; es alguien que no quiere cumplir sus deseos sino que solamente piensa en hacerlo dando rienda suelta a su imaginación. Es una persona que siempre se plantea la pregunta: ¿Qué pasaría si...? , pero la verdad es que no quiere ver el resultado. Sueña con lo que podría hacerle feliz; imagina, pero le da miedo no realizar el objetivo, perder el tiempo y, al fin y al cabo, fracasar. Muchos alumnos admitieron que es una persona a la que le falta voluntad y ambiciones, sin embargo, el buscador de sueños es una persona que siempre busca más posibilidades y ocasiones, es decir, tiene muchos deseos y se caracteriza por una persistencia en llegar a su objetivo, la autoestima y mucha ambición: quiere realizar sus ideas a pesar de los contratiempos y sabe sobrepasar fronteras. A ciencia cierta, podemos arriesgar la constatación de que los alumnos inconscientemente descubren la idea de salir de la zona de confort. 
Lo más interesante es que, también inconscientemente, los alumnos descubren la filosofía de Schopenhauer, con quien coinciden en que solamente el hombre es un ente que sabe soñar, pero el problema que tiene es que nada le satisface por mucho tiempo. Si cubre sus necesidades y realiza un deseo, en el mismo momento aparece el siguiente. Por otro lado, los alumnos descubren la idea de determinismo aunque tampoco lo denominan de esta manera técnica. Mencionan que la vida de la gente depende de su estatus financiero, es decir, el hombre rico sueña con cosas todavía más valiosas (un coche más caro, una piscina más grande...); no obstante, los más pobres sueñan con cosas que están un poco por encima de sus posibilidades (comida o ropa mejor). Sin embargo, la visión del mundo de los alumnos es mucho más positiva y la mayoría admite que para ganarse la vida hay que arriesgar un poco. Hay que ser valiente y tener esperanza, pero también hay que trabajar en cumplir sueños. Es necesario saber hacer frente a los problemas porque esto hace la vida más interesante y completa. Uno de los adolescentes llama la atención al hecho de que en la vida hay que ayudar a los demás a cumplir sus sueños, pero no desarrolla su opinión en qué manera habría que hacerlo.

Para acabar el análisis de este Aerolito hay que subrayar que solamente un alumno se describe a sí mismo como el soñador: "Soy un soñador. Me da miedo realizar mis sueños, pero espero que un día sepa luchar por mis propios deseos". Tres personas admitieron que son buscadores/buscadoras de sueños y siempre intentan "encontrar el mapa o el camino para cumplirlos".

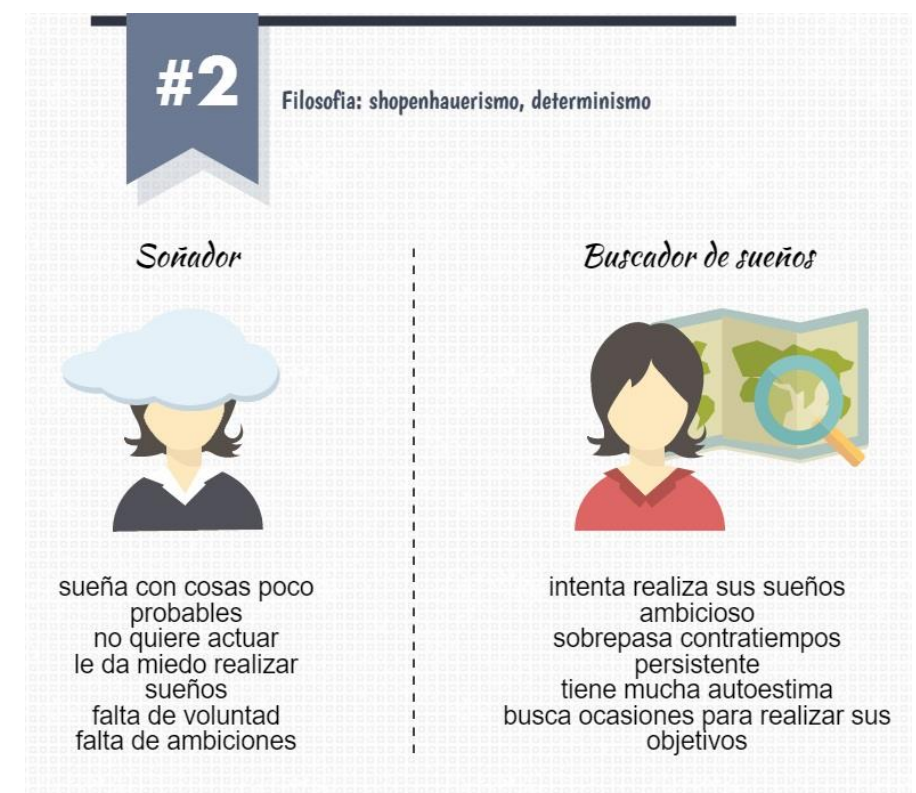

Imagen 2. Soñador vs. buscador de sueños (representación visual).

3.Estoy cansado de mañana. - Jestem zmęczony jutrem.

Es uno de los Aerolitos que les gustó más a los alumnos a la hora de conversar. En este caso los alumnos se fijaron en enumerar los problemas que producen su cansancio en la vida, les quitan la alegría de la vida y, a la vez, desmotivan (Imagen 3). Entre las causas más enumeradas fueron, en una gran simplificación, los adultos. Es decir, las expectativas de los adultos como los padres o los profesores (los deberes y una gran carga del material para asimilar en casa y en la escuela). Muchos alumnos admitieron 
que les da miedo la presión bajo la cual están en este momento ya que saben que pronto tendrán que elegir otra escuela para poder continuar la educación y muchos de ellos todavía no tienen ni idea de lo que les gustaría hacer en la vida - en el sistema educativo polaco los alumnos tienen que estudiar hasta los 18 años. Después de acabar el instituto, asisten a una escuela de formación profesional o a una escuela que les prepara para el examen de bachillerato (en el sistema polaco: liceo o técnico)—. El problema que notan los alumnos es también la crítica de los demás, pero ninguno especifica por parte de quién exactamente. En muchas ocasiones vuelven al tema de las expectativas, pero añaden que también exigen mucho de sí mismos.

Otro aspecto que los alumnos abordan es el problema de sus malas elecciones y las consecuencias que tienen que llevar, pero tampoco desarrollan el tema. Les cansa pensar siempre en lo que pasará mañana y lo hacen porque no quieren cometer errores. Los adolescentes polacos afirman que muchas veces no son capaces de evitarlo, pero no conocen el porqué de esta situación.

Otra cosa que resaltan es el pesimismo porque "la vida humana es aburrida y siempre tenemos que hacer lo mismo". Los alumnos presentan la vida como un círculo vicioso que nunca acaba. Mencionan el aburrimiento y la monotonía de la vida en la escuela y fuera de ella. Uno de los estudiantes escribe que en la vida hay que esperar mucho tiempo a que pase algo nuevo y positivamente sorprendente. Los alumnos afirman que la vida es un tipo de trance o como si estuviéramos en un estado hipnótico.

Se nota que los jóvenes están abatidos y el tema del cansancio les concierne mucho. Aquí también podemos ver un aspecto filosófico, ya que otra vez los alumnos hacen correspondencias inconscientes con la filosofía. Aunque no conocen las palabras de Séneca el Mayor, dicen que cometer errores es una cuestión humana (errare humanum est); además, afirman que son jóvenes y que es algo propio de los adolescentes. Les duele que los adultos exijan que piensen como adultos si todavía no lo son. En este caso, los alumnos perciben también la falta de lógica de la gente adulta: "Quieren que nos comportemos como adultos, pero por otra parte los jóvenes no pueden tomar muchas decisiones sin que los adultos se metan. A veces son cuestiones importantes como la elección de nuestra carrera, pero a veces son tonterías como qué comer o beber."

A pesar de todo el pesimismo y abatimiento que representan las redacciones, los alumnos recurren a la idea horaciana de carpe diem diciendo que hay que saber elegir bien, pero también disfrutar de lo que tenemos ahora, sin concentrarse tanto en el futuro. 


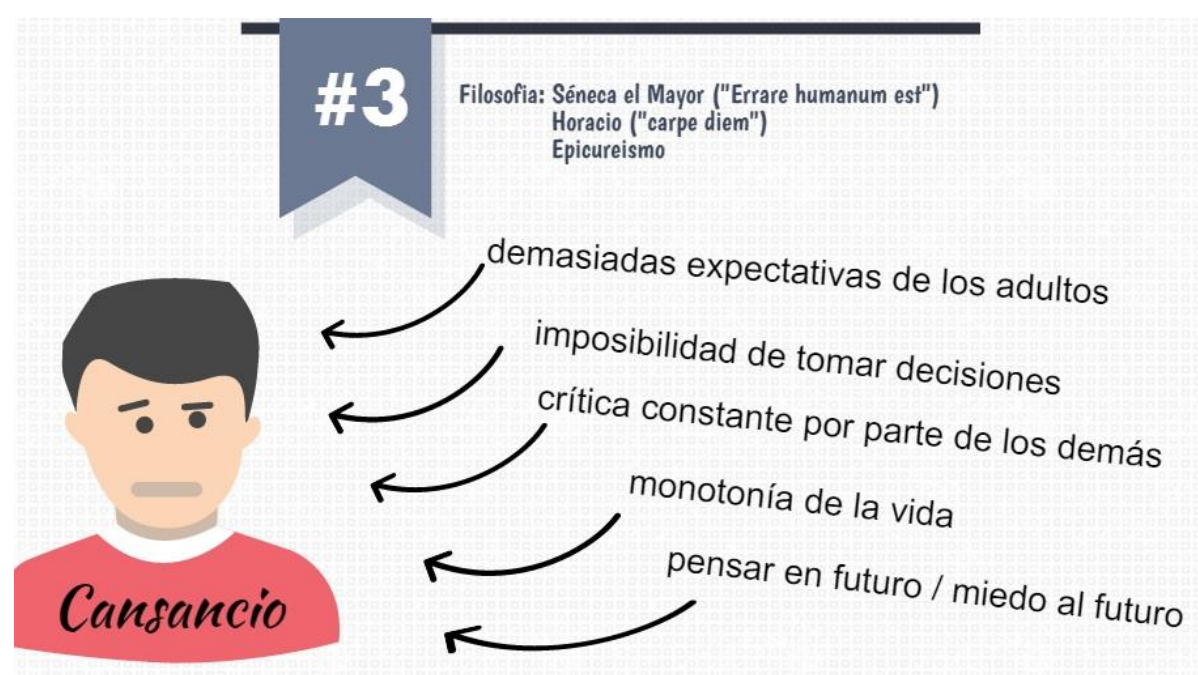

Imagen 3: Factores que provocan cansancio psíquico (representación visual).

\section{CONCLUSIONES}

Llegados al final de este gratificante proceso, sin lugar a dudas, podemos constatar que la actividad planeada y realizada en el Instituto Público número 26 de Mikołaj Rej de Łódz en Polonia, tiene un gran valor formativo y pedagógico. El objetivo de la actividad fue incentivar a los alumnos a conversar y escribir de una manera creativa tomando como base un Aerolito compuesto de una o dos frases como máximo, incluyendo las pautas del Ministerio de Educación en cuanto al fomento de la lectura y la escuela abierta al arte y cultura. No obstante, la actividad demuestra que, sobre todo, la literatura en general y la aforística microficcional oryana - los Aerolitos - que hemos empleado, puede tener una dimensión universal para los jóvenes en nuestra sociedad, aunque esté creada en un ámbito completamente diferente al suyo y por una persona mayor que ellos.

Una de las cuestiones más importantes para los profesores fue la posibilidad de observar a los alumnos a través de sus reflexiones, ya sea a través de conversaciones o de tareas de expresión escrita. En algunos casos, la actividad cumplió su rol terapéutico, lo cual puede ayudar al profesor-tutor a trabajar con el alumno con respecto a su desarrollo personal (autoestima, desarrollo de talentos...).

En cuanto a la creatividad del alumnado, habría que subrayar su capacidad de análisis y el descubrimiento inconsciente de nociones relacionadas con filosofía y cierto tipo de razonamiento lógico y bien estructurado.

La actividad y sus resultados deberían concienciar también a los profesores de que nuestra profesión no se ciñe solamente a ser transmisores de conocimientos, sino que sobre todo deberíamos ser los acompañantes en el camino de adquirirlo, es decir, cumplir ese papel de profesor como guía y mediador al que hemos hecho referencia anteriormente. En las manos del profesorado está enseñar aspectos programados por los jefes de estudio y el gobierno pero, además, nuestra tarea y obligación es incentivar a los alumnos a cultivar su pensamiento creativo y al desarrollo de actitudes positivas y críticas. A través del análisis del microrrelato, los alumnos fueron capaces de extraer muchas conclusiones, moralejas y enseñanzas. Una actividad cuidadosamente preparada 
puede cambiar su manera de pensar y, lo que sorprende más, disponer de esta vía como un proceso de catarsis y desahogo emocional.

Asimismo, el proyecto demostró que, sin muchos fondos materiales o un uso excesivo de las nuevas tecnologías, es posible invitar a los alumnos a reflexionar y a extraer buenas conclusiones para su vida.

\section{Listado 1:}

Algunas referencias de Aerolitos y el ser humano : "El hombre se imperfecciona cada vez más"; "Sé poeta un instante y hombre todos los días"; "Soy un sabelonada"; "El hombre camina con sus secretos"; "La muerte no se acaba nunca"; "Acuérdate de ahora mismo"; "Yo soy el rompeplatos"; "Solo estoy seguro de mi inseguridad"; "El único ismo practicado individualmente por el género humano es el egoísmo"; "Gracias a los ricos hay pobres, desgraciadamente"; "No soy un soñador, soy un buscador de sueños"; "¡No duermas tan deprisa!”; "Llevar el sufrimiento a cuestas es como un piano invisible"; "Si quieres verte y que te vean por encima de los demás, móntate en un caballo"; "El cansancio hace inocentes a los hombres"; "Los árabes dicen: "La lengua es la casa del ser»"; "«La humanidad se equivoca desde hace tres mil años» (Charles Fournier)"; "«No olvides que las palmeras se inclinan porque hay viento, no para darte dátiles» (Omar-al-Cháfar)".

\section{Listado 2:}

Algunas referencias de Aerolitos y temas universales: "Despedida de los amantes: «Hasta manzana», "Amoristad: un neologismo del escritor angolés Luandino Vieira"; "En la mujer dejo mis huellas digitales"; "En el cuarto de los amantes que no se oiga ningún ruido de la calle salvo la lluvia y el viento"; "La física nuclear no me sirve para comprender por qué lloro por amor"; "Entre hombres y mujeres todo son líos"; "Proverbio moscovita: «En las lágrimas de una mujer, el tonto ve solamente agua»"; "Alguien que me amaba mucho me mordió un día el pensamiento"; "Venimos de un agujero y vamos a otro agujero"; "Nos morimos por obedecer aun cuando la desobediencia acredita la vida"; "De la prensa: en el mundo, un suicidio cada veinte minutos"; "Nos dormimos cada noche para vivir con los ojos cerrados. Nos despertamos cada día para morir con los ojos abiertos"; "Un poema es la autobiografía del sueño"; "Los poetas son artistas del alma"; "Las pestañas salinas de los que lloran mucho"; "A veces me voy a pique porque me olvido del timón"; "Soy un sabelonada"; "El hombre se imperfecciona cada vez más"; "La humanidad es ya humanitud"; "El grito sale de los dientes, el suspiro de los pulmones, el silencio de los ojos"; "Acuérdate de ahora mismo"; "Estoy a punto de vivir"; "Yo soy el rompeplatos"; "Tristeza, suelta el trapo de la risa"; "Solo estoy seguro de mi inseguridad"; "Si tanto miro relojes y almanaques, será porque estoy fuera del tiempo"; "Ha llegado la hora de vivir al borde del abismo"; "Gracias a los ricos hay pobres, desgraciadamente"; "No enseña la bondad, la maldad sí"; "El cansancio hace inocentes a los hombres"; "Si lloro es porque tengo lágrimas"; "Sentir las sensaciones anónimas".

\section{Referencias Bibliográficas}


Sánchez Corral, L. (2003). Didáctica de la literatura: relaciones entre el discurso y el sujeto. En A. Mendoza Fillola (coord.) Didáctica de la Lengua y Literatura (pp. 291-317). Madrid: Pearson Educación.

Ory de, C. E. de (2006). En un café. En El desenterrador de vivos (p.37). Barcelona: Galaxia Gutemberg. Círculo de Lectores.Diario (1944-1955; 19551975; 1976-2000). Cádiz: Servicio de publicaciones de la Diputación de Cádiz.

Parrado Collantes, M. (2013). La senxualidad en Carlos Edmundo de Ory. En M. T. Navarrete Navarrete y M. Gallo Soler (eds.), Ay, iqué triste es toda la humanidad! (pp. 143-152). Italia: Aracne.

- (2015). Las fundaciones de poetas como herramienta didáctica: la Fundación Carlos Edmundo de Ory. En J. Bień y J. Kudełko (Dir.) Nuevas perspectivas del hispanismo polaco: estudios de lingüística y literatura (pp. 50-63). Lublin: Biblioteca Polsko - Iberyjska.

Romero, M. F. y Wilczyńska, A. (2016). La formación lectora y literaria (2015) o Cómo reflexionar sobre l'horrible perill de la lectura (2015): diálogos en torno a la obra y el pensamiento del profesor Josep Ballester, Revista de Lingüística y Lenguas Aplicadas, 11, 71-72.

Vicente-Yagüe Jara, M. I. de (2015). Fomento de la lectura: el plan lector. El canon formativo en la educación lectoliteraria. En P. Guerrero Ruiz y M.T. Caro Valverde (coord.) Didáctica de la lengua y educación literaria (pp. 297-304). Madrid: Pirámide.

VV.AA (2008). Wislawa Szymborska. En Krystyna Rodowska (selección, traducciones y notas) Poesía polaca contemporánea (pp. 28-31). México: Universidad de México, Coordinación de Difusión Cultural. Dirección de Literatura.

\section{Webgrafía}

Aerolito [Definición]. Recuperado de: http://dle.rae.es/?id=0u6PYDr (Consultado el 16/9/2016).

Ripoll, J.R. (2013). La memorya oryental. (A propósito de los aerolitos y ensayos de Carlos Edmundo de Ory). En Poemad. Revista de poesía, número 4 (dedicada a Carlos Edmundo de Ory): Recuperado de: https://goo.gl/AeNyfR [Consultado el16/9/ 2016].

En base al artículo 35 ust, 2 pkt 1 del 7 de septiembre de 1991 r. sobre el sistema de educación (Dz. Uz 2015 r. poz 2156, z późn. Zm). Recuperado de: https://goo.gl/JrSGMW (Consultado el 16/9/2016). 